\title{
Abdominal Kitle ile Başvuran Imperfore Himen Olgusu
}

\author{
${ }^{1}$ Ömer Faruk Doğan, ${ }^{2}$ Metin Şentürk, ${ }^{2}$ Samet Aslan, ${ }^{3}$ Tufan Öge, ${ }^{3}$ Yunus Aydın \\ ${ }^{1}$ Şanlıurfa Kadın Doğum Hastanesi, Şanlıurfa. \\ ${ }^{2}$ Osmangazi Üniversitesi Tıp Fakültesi Kadın Hastalıkları ve Doğum AD, Eskişehir. \\ ${ }^{3}$ Osmangazi Üniversitesi Tıp Fakültesi Kadın Hastalıkları ve Doğum AD, Eskişehir. \\ e-posta: aydin.yunus@yahoo.com
}

\begin{abstract}
ÖZET: Amaç:Adölesan dönemde pelvik kitle ile başvuran imperfore himen olgusu sunumu Bulgular: İmperfore himen nedenli hematokolpos gelişmiş bir adölesan kız olgusu sunuldu. Bizim olgumuzda alt kadran ağrısı ve pelvik kitlenin primer amenore ile birlikte eş zamanlı görülebildiği gösterildi. Himenotomi sonrası annuler halka tarzında himen şeklinde restore edildi. Sonuç: Pelvik kitle ile başvuran primer amenoreik adölesanlarda altta yatan imperfore himen olasıllğı göz önünde bulundurulmalıdır.
\end{abstract}

ANAHTAR KELIMELER: Adolesan, Hematokolpos, İmperfore himen, Primer amenore

SUMMARY: Study objective: To document an unusual cause of abdominal pain and pelvic mass in premenarcheal adolescent girl.Results: The case of hematocolpos in adolescent girl due to imperforate himen was reported. Our case manifested lower abdominal pain and pelvic mass concomittant with primary amenorrhea. Himenotomy was performed and the annular himen ring was restorated.Conclusion: We should bear in mind the probability of imperforated himen in primarily amenorrheic premenarcheal girls presented with abdominal mass

KEY WORDS: Adolescent, Hematocolpos, İmperforated himen, Primary amenorrhea

\section{Giriş}

Himen mesodermal doku kalıntısı olup embryonel dönemin sonlarına doğru incelerek perforasyon gelişir. Perforasyon oluşmasındaki eksiklik sonucu perde şeklinde mesodermal doku kalmasina ise imperfore himen denmektedir. Imperforate himen yaklaşık olarak 2000 kadında bir görülmekle birlikte sıklıkla sporadiktir $(1,2)$.Hemen hemen tüm vakalarda tanı adolesan döneminde primer amenore veya pelvik ağrı incelemesi esnasında konmaktadır. Pelvik ağrı, menstruasyon döneminde daha fazla olduğu için ataklar halinde gelir ve hastalar sıklıkla ara dönemlerde göreceli olarak rahatladıkları için tanıda gecikmeler olabilir $(3,4)$. Sıklıkla menstruasyon döneminde oluşan kanama vajende birikir ve tekrarlayan menstruasyon atakları ile kanama dışarı boşalamaması nedeniyle retrograd olarak peritoneal boşluğa dönebilir ve endometriozise bile neden olabilir. Dolayıs1 ile retrograd akım olabilme seviyesine göre semptomlar değişmekle birlikte bazı hastalarda minimal retrograd akım olması nedeniyle vajen iyice genişleyebilir. Biz bu vaka sunumu ile imperfore himen sonucu $>20 \mathrm{~cm}$ hematokolpos gelişmesi nedeniyle abdominal kitle öntanısı ile ilk olarak değerlendirilen bir hasta kliniğini paylaşmak istedik. Amacımız, primer amenoreye eşlik eden siklik pelvik ağrllı adölesanlarda olduğu gibi abdominal kitle nedeniyle de başvuran adölesanlarda imperfore himenin hatırlanmasını sağlamaktır.

\section{Olgu}

14 yaşındaki kız hasta 5 gündür devam eden karın ağrısı ve karında şişkinlik şikayeti ile adölesan polikliniğimize başvurdu. Hastanın öyküsünde bu ağrının 2 yıldır ara ara tekrarlamakta olduğu ve bu ağrı nedeniyle 
daha önceki dış merkez başvurularında ağrilı dönemlerde intramusküler analjezik kullandığı öğrenildi. Henüz daha adetlerinin başlamadığı öğrenilen hasta son 6 aydır artan karın şişkinliği ifade etmekte idi. Yapılan genel sistemik muayenede sekonder seks karakterlerinin geliştiği, batında ise sola deviye olan ve umbilikus'a dek uzanan sert, düzgün sinırlı, soliter yapıda kitlesel yapı palpe edildi. Yapilan jinekolojik muayenede diş genital organlar normal olmakla birlikte vestibülün izlenmesi gerektiği yerde mavi refle veren (1kınma olmaksızın) ve hematokolposu düşündüren bombeleşme saptandi. Rektal muayenede ise vajen aksı boyunca oluşmuş olan kitlesel yapının rektumu tıkayacak şekilde aşağı doğru baskı yaptığı saptandı. Yapılan abdominal ultrasonografide umbilikusa dek uzanan ve tüm alt batın-pelvis bölgesini dolduran orta derecede heterojen, buzlu cam görünümünde hematom ile uyumlu olabilecek yap1 $(25 \times 17 \mathrm{~cm})$ izlendi. $\mathrm{Bu}$ yapının üst noktasında $45 \times 25 \times 27 \mathrm{~mm}$ boyutlarında uterus saptand 1 ve kavitede hematometra ile uyumlu $6 \mathrm{~mm}$ alan izlendi. Overler net olarak izlenemeyen hastada acil olarak çekilen abdominopelvic MRI'da uterus sola deviye, vajen-serviks bölgesinde $9,5 * 10 * 20 \mathrm{~cm}$ boyutlarında T1 ağırlıklı çalışmalarada hiperintens T2 ağırlıklı çalışmalarad ahipo-izointens kanama ile uyumlu bulgular saptandı (şekil 1). İmperfore himen nedeniyle oluşan hematokolpos öntanısı ile acil olarak genel anestezi altında operasyona alınan hastaya litotomi pozisyonunda parsiyel himenektomi yapıldı ve yaklaşık olarak 600 cc koyu kıvamlı hematom ile uyumlu mayi aspire edildi himen kenarlarında hemostaz sağlanarak eversiyon uyguland.

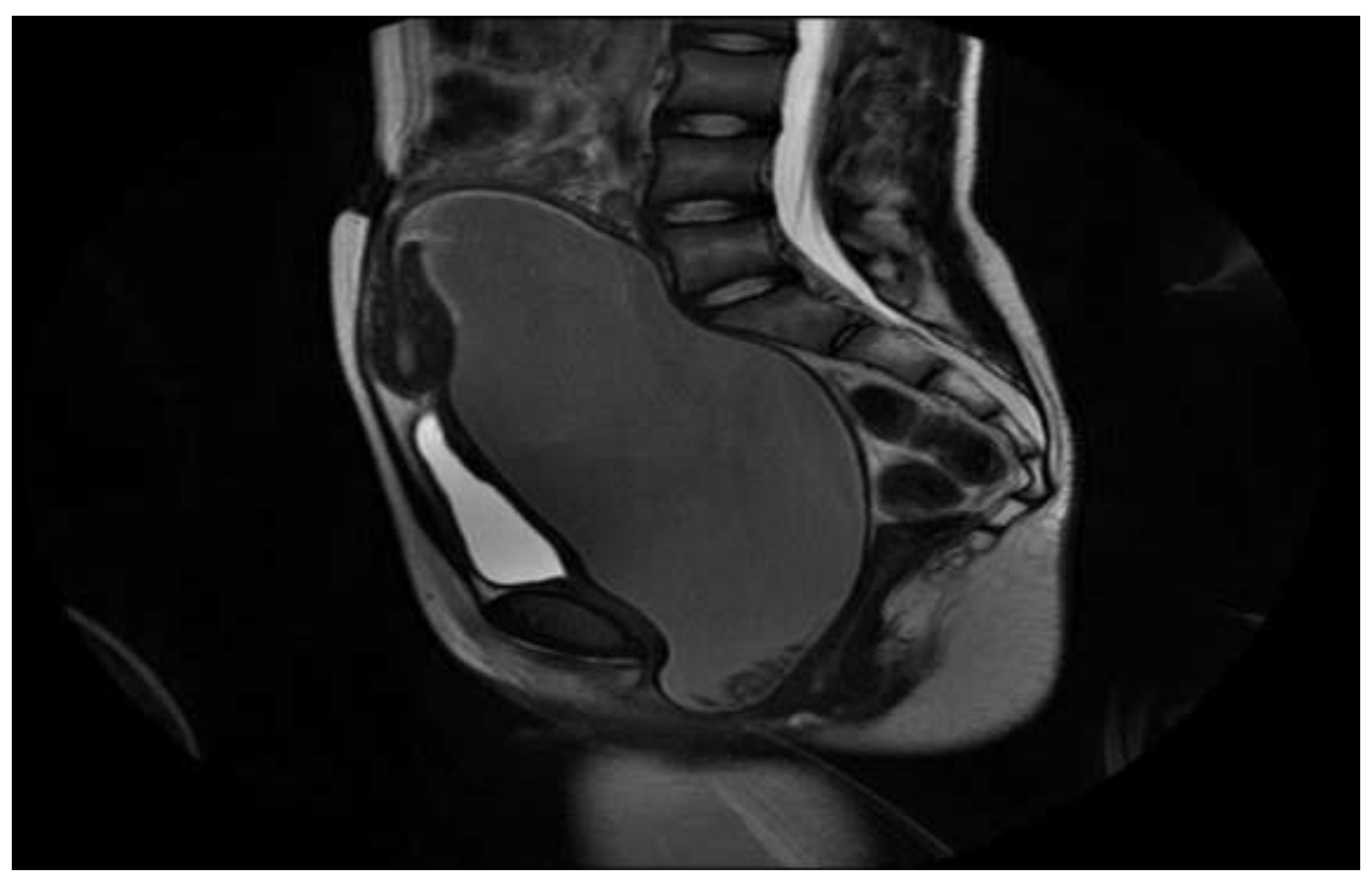

Şekil 1. MRI'da vajen-serviks bölgesinde $9,5 * 10 * 20 \mathrm{~cm}$ boyutlarında kanama, hematokolpos ile uyumlu görünüm. Uterus hematokolposun proksimaline, batın önduvart ile hematokolpos arasinda görülmekte. 


\section{Tartışma}

IH'e her ne kadar çok sık rastlanmasa da McCann ve ark.'nın yaptığı tanımlayıcı gözlemsel bir çalışmada 10 ay ile 10 yaş arasında incelenen kizlarda görülme sıklığı $\quad 1.2 \%$ olarak bildirilmiştir (5). Sadece anamnez ve fizik muayene ile bile tanı konulabilmesine rağmen bizimde sunduğumuz olgudaki gibi tanıda gecikmelerin olması, hastaya ilk yaklaşımın ne kadar önemli olduğunu göstermektedir. Olgular sıklıkla adetler başlayana dek asemptomatiktir. Klasik olarak beklenen başvuru şekli ise sekonder seks karakterleri gelişmesine ragmen menarşıı başlamaması ile birlikte siklik pelvik ağrıların olmasıdır. Düzenli olarak menstruasyonun gerçekleşmesi ancak menstrual kanın vajinal yoldan boşalamaması sonucu hematokolpos, hematometra ve hematosalpinx gelişebilir. $\mathrm{Bu}$ aşamada iyi bir anamneze eşlik edecek olan dikkatli bir fizik muayene ve genital muayene ile kolayca tanı konulabilir. Ancak sunduğumuz olguda olduğu gibi, tanı konmadan paliativ tedaviler ile (analjezik tedavisi gibi) klinik tablo daha da komplike hale gelebilir ve pelvik kitle tanısı ile hastalar başvurabilir. Uzun dönem paliativ tedaviler eşliğinde retrograde kanama artışı ile endometriozis gelişmesi muhtemeldir. Her ne kadar bizim olgumuzda saptanmamış olsa da, idrar retansiyonu nedeniyle olan başvurularda da IH akılda tutulmalıdır $(6,7)$. Sekonder seks karekterleri varlığında primer amenore, pelvik ağrı ve pelvik kitle ayırıcı tanısinda IH, transverse vaginal septum, longitudinal vaginal septum, vaginal agenesis ve cervical atresia düşünülmelidir. IH'nin özellikle transverse vaginal septumdan ayrımında Valsalva manevrası önemlidir; IH'li olgularda Valsalva ile vestibüler bölgede mavi refle veren bombeleşme (bulging) olmakta iken transvers septumda izlenmez. Vaginal agenezi, cervical atrezi ayırıcı tanısında ise MRI oldukça önemli olup altın standart ayırıcı tanı aracidır (8).IH olgularında standart tedavi yaklaşımı cerrahi himenektomi veya himenetomidir. $\mathrm{Bu}$ yaklaşımlarda $\mathrm{X}, \mathrm{T},+$ insizyonları kullanılabilir ve gerekli vakalarda fazla himen dokusu çıkartılabilir (9). Acar ve ark. tarafindan bildirilen bir diğer yöntemde ise anüler olarak himen orta noktasından parça çıkartılmasını takiben hemostaz sağlanması ile foley konulabilir (10). Acar ve ark.'nın bildirdiği yöntem; kültürel ve kişisel olarak himen'in önemli olduğu vakalarda daha tercih edilebilir gibi görülmektedir (10). Biz de olgumuzda annuler himenektomi yaparak kalan himen dokusunda annuler yapıyı korumaya çalıştık. Sonuç olarak; primer amenore nedeniyle başvuran kronik pelvik ağrılı olgularda anamnez ve genital muayene çok önemlidir. Abdominal kitle nedeniyle başvuran adölesanlarda IH mutlaka akılda tutulmalidir.

\section{KAYNAKLAR}

1. Parazzini, F. Cecchetti, G. (1990). The frequency of imperforate himen in Northern Italy. Int $J$ Epidemiol. 19:763-7.

2. Posner, J.C. Spandorfer, P.R. (2005). Early detection of imperforate himen prevents morbidity from delays in diagnosis. Pediatrics.115:1008-12.
3. Hall, D.J. (1999). An unusual case of urinary retention due to imperforate himen. J Accid Emerg Med. 16:232-6.

4. Letts, M. Haasbeek, J. (1990). Hematocolpos as a cause of back pain in premenarchal adolescents. $J$ Pediatr Orthop. 10:731-8. 
5. McCann, J. Wells, R. Simon, M. et al. (1990). Genital findings in prepubertal girls selected for nonabuse: a descriptive study. Pediatrics. 86: 42833.

6. Chircop, R. (2003). A case of retention of urine and haematocolpometra. Eur $J$ Emerg Med.10: 244-5.

7. Nazir, Z. Rizvi, R.M. Qureshi, R.N. Khan, Z.S. Khan, Z. (2006). Congenital vaginal obstructions:varied presentation and outcome. Pediatr Surg Int. 22:749-53.
8. Burgis, J. (2001). Obstructive Mullerian anomalies: Case report, diagnosis, and management. Am J Obstet Gynecol. 185:338-43.

9. Te Linde, R.W. Rock, J.A. Jones, H.W. (2003). Te Linde's Operative Gynecology, (9th ed.). Philadelphia, Lippincott Williams \& Wilkins

10. Acar, A. Balci, O. Karatayli, R. Capar , M. Colakoglu, M. (2007). The treatment of 65 women with imperforate himen by a central incision and application of Foley catheter. BJOG. 2007; 114:1376-9. 